\title{
Modeling of the Direct Shear Test from the Finish Elements Method
}

\author{
Kempena Adolphe, Mbilou Urbain Gampio, Mouanda Makanda Emilienne Greve, \\ Rafael Guardado Lacaba, Antonio Olimpio Gonçalves, and Boudzoumou Florent
}

\begin{abstract}
Soil improvement using the geosynthetic technique is usually used for fine and friable soils. This technique provides a reinforced soil with high shear strength. The interest is certainly well displayed. Indeed, this work aims to numerically assess the geosynthetics placement influence on the fine sand properties. For this purpose, a reduced model has been designed to initially allow simulating the geosynthetic layer incorporation into an unsaturated soil while maintaining vertical stress and measuring the lateral stress generated during this incorporation. The scale model makes it possible to assess the possible displacements experienced by the soil during the direct shear test. Numerical modeling then made it possible to confirm the experimental results and verify these displacements behavior. Numerical modeling was carried out by applying the finite element method considering a behavioral law of the MohrCoulomb type for soil and geosynthetics. The results obtained by numerical modeling confirmed the direct shear test functionality in the laboratory. This opens the door to further studies about the geosynthetics effect in the soil.
\end{abstract}

Key words - geosynthetics, finite elements, numerical modeling, Mohr-Coulomb, shear strength.

\section{INTRODUCTION}

Brazzaville has experienced in recent years a vast campaign of urban growth and expansion of the city to the detriment of areas potentially at high risk of landslide, which has been a major challenge for researchers and for civil authorities [1]. Therefore, the use of different techniques and solutions for soil reinforcement has become necessarily essential in order to improve the land stability and safety. One of the most used solutions in this context, we find the reinforcement by geosynthetic layers which consist in superimposing layers of compacted soil and geosynthetics.

This technique has been widely approved and adopted, given the efficiency of the support provided and the simplicity of its implementation. From this perspective, the problem addressed in this work consists in studying the not reinforced and reinforced soils mechanical behavior by geosynthetics in order to determine the mechanisms inducing their performance and to be able to compare them in a quantitative manner [1], [2].

Submitted on September 15, 2021

Published on October 31, 2021.

Kempena Adolphe, Marien Ngouabi University, Brazzaville, Congo.

(e-mail: akempena@ gmail.com)

Mbilou Urbain Gampio, Marien Ngouabi University, Brazzaville,

Congo.

(e-mail: gampiombilou ${ }^{\circledR}$ gmail.com)

Mouanda Makanda Emilienne Greve, Marien Ngouabi University, Brazzaville, Congo.

(e-mail: mouandaeg@gmail.com)
The study of soil behavior requires a mandatory passage through a phase of determining the mechanical characteristics in the soil/soil and soil/geosynthetic interface through mechanical tests [3]. In addition to this, it is noted that the soils stability in geotechnical projects is an indispensable condition, and their properties can be improved by reinforcement techniques. This is why structures design using geosynthetics has made it possible to understand the beneficial effects of a soil planar reinforcement [4].

Soils constitutive law being particularly complex, a soil fracture does not only pose a problem of fracture kinematics choice. It is also necessary to define when the rupture occurs in the tests which serve to measure the soil shear strength. Such as direct shear tests which allow the measurement of soil strength parameters, either the angle of friction $\left(\varphi^{\prime}\right)$ or the cohesion ( $\left.c^{\prime}\right)$ and the angle of dilatancy $(\psi)$. On the other hand, the computer science development has facilitated geotechnical projects analysis of using numerous finite element calculation codes. These allow the elastic, elastoplastic, elastoviscoplastic analysis in $2 \mathrm{D}$ or $3 \mathrm{D}$ and the large displacements experienced by structures and soils [5].

Most of classical stability calculation methods in soils mechanic are based on the plasticity theory. In this theory we assume that the strains remain small and reversible as long as we remain in constraints space within a certain domain. This domain boundary is called flow boundary (or surface). As soon as the stress state in the middle reaches this border and irreversible plastic deformations appear [6]. Soils rupture does not only pose a choice problem of rupture kinematics. It is also necessary to define when the rupture occurs in the tests which measure the soil tensile strength which is usually referred to as the shear strength [7].

The technology progress is leading engineers to carry out projects that are more and more complex, expensive and subject to increasingly severe security constraints. To carry out these projects and given the analytical methods complexity for materials strength, engineer uses methods that allow him to simulate complex physical systems behavior. Conditioned by the progress made in the computer field and the achievements of mathematics in the energy theory, the

Rafael Guardado Lacaba, Higher Institute of Mines and Metallurgy, Moa, Cuba

(e-mail: rafaelguardado2008@gmail.com)

Antonio Olimpio Gonçalves, Agostinho Neto University, Luanda, Angola.

(e-mail: tonygonçalves72@ ${ }^{\circledR}$ hotmail.com)

Boudzoumou Florent, Marien Ngouabi University, Brazzaville, Congo

(e-mail: boudzoumouf ${ }^{\circledR}$ gmail.com) 
finite element method eventually became the most efficient of numerical methods given its application wide field [8].

\section{MATERIALS AND METHODS}

\section{A. Materials and Experimental Study}

The soil used for this study is a soil sample in a $30 \mathrm{~kg}$ pocket at a depth of approximately $0.75 \mathrm{~m}$, precisely at the foot of the slope in the Djiri-Magnanga district in northern zone of Brazzaville City (Fig. 1).

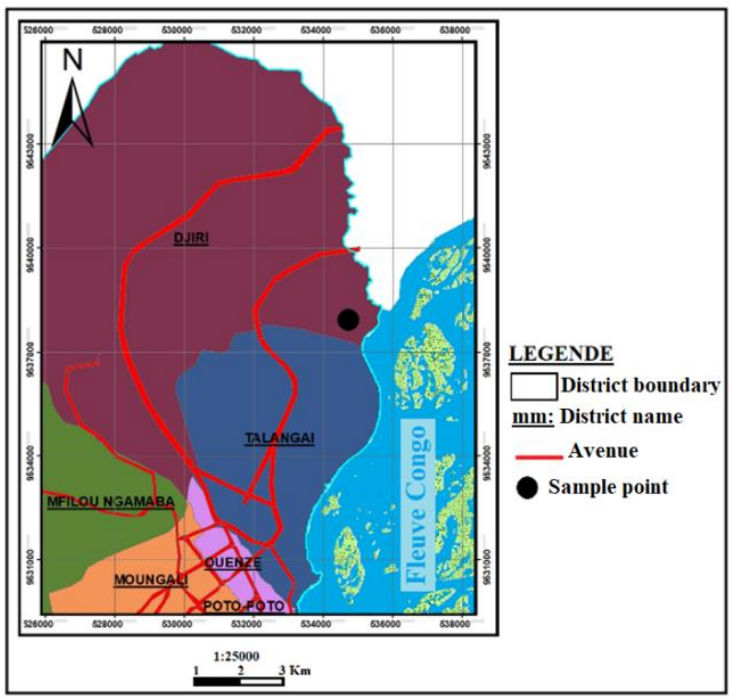

Fig. 1. Study area location.

\section{B. Laboratory Tests}

- Particle size analysis;

- Specific densities of solid grains;

- Atterberglimits;

- Proctortest;

- Shear test.

The equipment used in this section can be located in the Faculty of Sciences Road Geotechnical Laboratory of the Agostinho Neto University (Luanda, Angola).

\section{Particle Size Analysis}

The soil studied is sand taken from a $30 \mathrm{~kg}$ bag. It is done by dry sieving after washing for soils with elements greater than $80 \mu \mathrm{m}$ and by sedimentation for elements less than $80 \mu \mathrm{m}$. Particle size analysis of soil up to a diameter of $80 \mu \mathrm{m}$ is done using a series of sieves.

\section{Particle Size Test by Sieving}

\section{1) Test objective}

It is to determine the quantity (mass) of grains with diameter up to $80 \mu \mathrm{m}$ there are two methods:

- Wet sieving.

- $\quad$ Dry sieving after washing (NFP94-056/1996).

\section{E. Equipment}

- Sieve in general, square mesh screens;

- Common dimensions: $80 \mathrm{~mm}-50 \mathrm{~mm}-32 \mathrm{~mm}$ - $20 \mathrm{~mm}$

- $10 \mathrm{~mm}-5 \mathrm{~mm}-2 \mathrm{~mm}-1 \mathrm{~mm}$;

- $0.4 \mathrm{~mm}-0.2 \mathrm{~mm}-0.08 \mathrm{~mm}(=80 \mu \mathrm{m})$;

- balance.

\section{F. Particle Size Test by Sedimentometry}

\section{1) Test objective}

The aim of sedimentometry is to determine the weight distribution of the soil grains according to their size for fine particles smaller than $0.08 \mathrm{~mm}$. Indeed, when the particles diameter is small, sieving no longer makes it possible to obtain good results (NFP94-057 / 1992).

\section{G. Mechanical Tests}

In order to obtain a better knowledge of the soil mechanical behavior before and after the reinforcement the following mechanical tests were carried out:

\section{H. Modified Proctor Test}

The Proctor test is carried out according to the standard [NF P 94-093]. The purpose of the Proctor test is to determine the optimum water content and the maximum density of a material subjected to standardized compaction of a given intensity.

\section{Direct Shear Test}

\section{1) Test on unreinforced samples}

The goal is to put the shear plane in the middle of a layer, so vertically the sample is considered homogeneous.

\section{2) Equipment}

The specific apparatus under test comprises (see Fig. 2).

- The shear box with internal section $\mathrm{A}=100 \mathrm{~cm}^{2}$ and a height of $1.9 \mathrm{~cm}$ composed of two half-boxes.

- The device for applying the desired normal force and the device producing the relative horizontal displacement between the two half-boxes;

- A dynamometric ring indicating the shear forces;

- The force sensors:

- The horizontal sensor of the digital ruler type, records the movements of the upper box and allows the speed regulation of this box;

- The vertical sensor, also with a digital ruler type, measures the settlement or general materials dilantacy during the test.

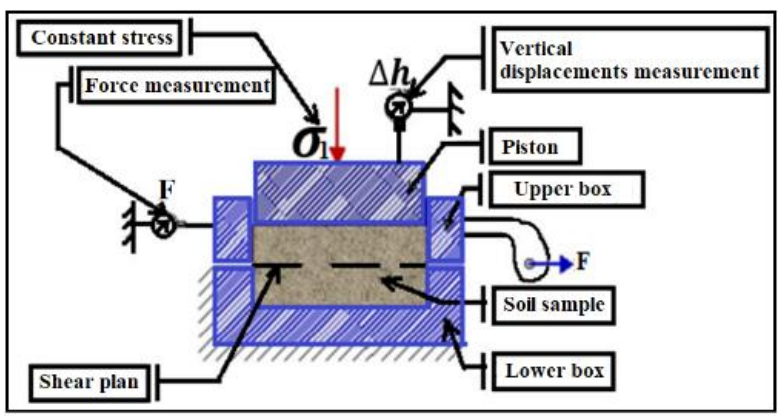

Fig. 2. Schematic of the shear box

\section{J. Reinforced Samples Test}

The reinforcement layer is positioned in the middle of the sample height between the fixed lower box and the movable upper box of the test device (Fig. 3). 


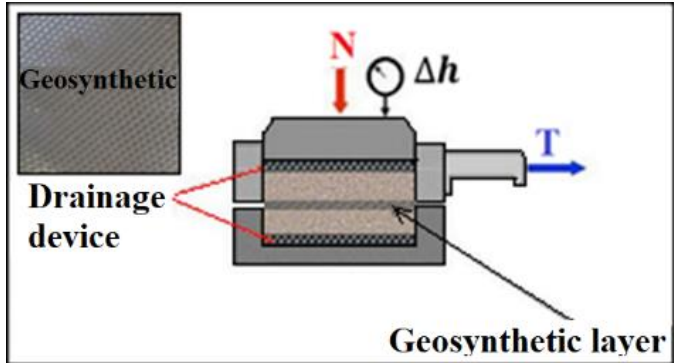

Fig. 3. Position of the geotextile layer in the sample.

\section{K. Shear Test Modeling}

The goal is to propose a geotechnical model for the direct shear test for this, we carried out the test with application of a constant normal stress on the upper half box which can move only in the horizontal direction and a variable tangential stress on the upper half box until the model plasticization. The behavior of Mohr-Coulomb used in the present study presents a perfectly plastic elastic behavior without hardening. It has a great use in geotechnics given the results obtained in the calculations. In Mohr's plane the intrinsic line is represented by: $\tau=\sigma_{\mathrm{n}} \tan \varphi+\mathrm{c}$ where $\sigma_{\mathrm{n}}$ and $\tau$ are respectively the normal and shear stresses and $c$ and prespectively the cohesion and the friction angle of the material (Fig. 4).

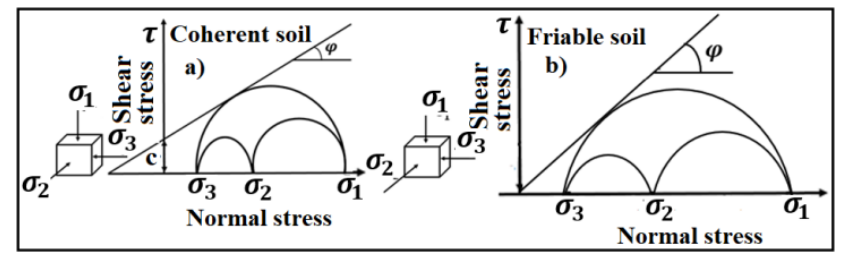

Fig. 4. Intrinsic curve of Morh-Coulomb model.

The model requires to determine five parameters. The first two are the Young's modulus (E) and the Poisson's ratio (v) called elasticity parameters, the other two are the cohesion (c) and the friction angle $(\phi)$ respectively and the angle of dilatancy $\psi$. These are classic geotechnical parameters admittedly often provided by laboratory tests, but necessary for strain or stability calculations.

\section{Simulation by Finite Element Method}

In order to install a model to carry out a simulation by the finite element method we started by defining the geometry, introducing the models behavior, introducing the structural elements, specifying the initial conditions and the boundary conditions, mesh, calculating initial stresses, resetting the displacements, introducing the loading, applying the required number of cycles, the model response examination, then introducing the required modifications.

\section{Geometry and Mesh}

The analysis is carried out within the plane strains framework. The flow being supposed non-existent and calculations are made in effective and short-term stresses that is to say with the soil effective shear parameters (effective cohesion $c^{\prime}$ and internal friction angle $\varphi^{\prime}$ ) and without drainage. The model size is set so that its borders are absorbent and they are as far away from the slope as possible. The mesh consists of triangular elements at 15 nodes.

\section{$N$. Initial Conditions and the Boundary Conditions}

The boundary conditions are an obligatory phase in a grid construction, generally it consists in imposing along the lateral borders of the model and its base the following conditions: Horizontal displacement on the lateral edges $=0$, displacement on the lower base of the model $=0$ and the actions considered are the soil mass weight.

\section{O. Calculation Procedure}

The purpose of the series of calculations carried out is to determine shear stresses values. The initial state is characterized by stresses of geostatic type, the computation of the reference model considered is done in two phases: A plastic computation with the Mohr-Coulomb criterion in undrained conditions and a computation shear stresses values by the "phi-c reduction" method.

\section{P. Hypothesis and Model Geometry}

\section{1) General data hypothesis}

- The strains are considered plane.

- The influence of interfaces is negligible (the interfaces density is different from that of the soil).

\section{2) Model geometry}

The project is not symmetrical (Fig. 4), it will be modeled by a plane geometric model (2D) with $1 \mathrm{~m}$ of wide by $1 \mathrm{~m}$ of deep. This model is shown in Fig. 6.

\section{Q. Initial Conditions and Boundary Conditions}

The boundary conditions are taken into account by blocking horizontal displacements (horizontal displacement on the lateral edges $=0$ ) and vertical for the lower limit and the distant limits in the $\mathrm{x}$ direction (displacement on lower base of the model $=0$ ) because the boundary conditions are an obligatory phase in the construction of a finite element grid. The modeling is carried out in two stages: initially we carried out the mesh (Fig. 6). The mesh generation is done automatically then in a second step we have represented it in an $\mathrm{x}-\mathrm{y}$ plane. For this application we have plotted the horizontal displacement measured for the upper half-box only and the horizontal displacements (vertical fixities) for the lower half-box we block everything (total fixities).

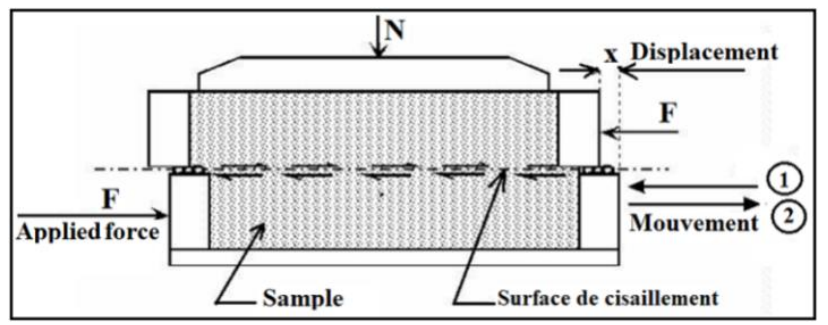

Fig. 5. Shear box section.

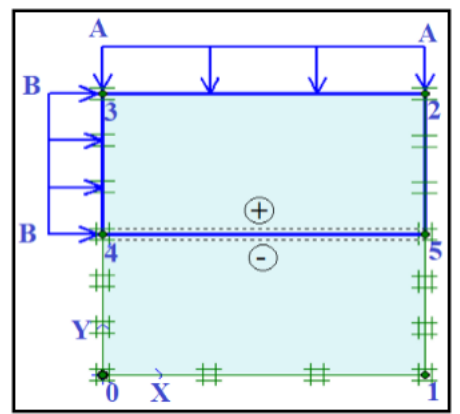

Fig. 6. Geometric model of the shear box. 
The box is $1 \mathrm{~m}$ of wide, $1 \mathrm{~m}$ of high, consisting of two half boxes, one fixed (lower) the other moves horizontally (upper). Interfaces are used to produce the interaction effects between soil and structures.

Numerical modeling by calculation code requires the definition of a few parameters. The values of these parameters are often approximated from the laboratory tests results. The specific geotechnical characteristics to the calculations are grouped together in the Table I.

\section{R. Geotechnical Data}

The specific geotechnical characteristics are grouped in Tables I, II and III.

\section{1) Material characteristics}

\section{1) Soil and interface properties}

\begin{tabular}{ccc}
\multicolumn{3}{c}{ TABLE I: GEOSYNTHETIC CHARACTERISTICS } \\
\hline & Unit & Geosynthetic \\
\hline Stiffness of the geogrid $\mathrm{J}$ & $\mathrm{kN} / \mathrm{m}$ & 500 \\
Poisson's ratio $v$ & - & 0,4 \\
Thickness & $\mathrm{m}$ & $5 \times 10^{-3}$ \\
Friction angle $\varphi_{\mathrm{gs}}$ & $\circ$ & 38 \\
Cohesion $\mathrm{c}_{\mathrm{gs}}$ & $\mathrm{kPa}$ & 0 \\
Spring stiffness $\mathrm{k}$ & $\mathrm{kPa} / \mathrm{m}$ & $10^{3}$ \\
\hline
\end{tabular}

TABLE II: SOIL PROPERTIES TYPE

\begin{tabular}{cccc}
\hline Parameters & Name & Fine sand & Units \\
\hline Model type & Model & Mohr coulomb & - \\
Behavior type & Type & Drained & - \\
Dry density & $\gamma_{\mathrm{sat}}$ & 18,1 & $\mathrm{KN} / \mathrm{m}^{3}$ \\
Wet density & $\gamma_{\mathrm{d}}$ & 13,7 & $\mathrm{KN} / \mathrm{m}^{3}$ \\
Horizontal permeability & $\mathrm{K}_{\mathrm{x}}$ & 8,6 & $\mathrm{~m} / \mathrm{j}$ \\
Vertical permeability & $\mathrm{k}_{\mathrm{Y}}$ & 8,6 & $\mathrm{~m} / \mathrm{j}$ \\
Young's modulus & $\mathrm{E}_{\mathrm{ref}}$ & $1,650^{*} 10^{4}$ & $\mathrm{KN} / \mathrm{m}^{2}$ \\
Poisson coefficient & 0 & 0,3 & $\mathrm{KN} / \mathrm{m}^{2}$ \\
Cohesion & $\mathrm{C}$ & 1,7 & 0 \\
Friction angle & $\varphi^{\prime}$ & 35 & 0 \\
Angle of dilatancy & $\Psi$ & 0 & - \\
Interface stiffness factor & Rinter & - & - \\
Permeability of the & Permeability y & - & \\
interface & & &
\end{tabular}

The $\mathrm{R}_{\text {inter }}$ parameter is defined as so:

Tan $\varphi_{\text {interface }}=\mathrm{R}_{\text {inter }} \tan \varphi_{\text {sol }}$ et $c_{\text {interface }}=\mathrm{R}_{\text {inter }} \mathrm{c}_{\text {sol }}$

TABLE III: PROPERTIES OF THE UPPER HALF-BOX

\begin{tabular}{cccc}
\hline Parameters & Name & Upper half-box & Units \\
\hline Model Type & Elastic & & \\
Normal stiffness & EA & $7,5.10^{6}$ & $\mathrm{KN} / \mathrm{m}$ \\
Bending stiffness & E1 & $10^{6}$ & $\mathrm{kNm} / \mathrm{m}$ \\
Thickness & d & 1,265 & $\mathrm{M}$ \\
Equivalent weight & $\mathrm{W}$ & 10 & $\mathrm{KN} / \mathrm{m} / \mathrm{m}$ \\
Poisson coefficient & $\mathrm{V}$ & 0 & \\
\hline
\end{tabular}

\section{S. Generation of the Mesh}

We set the fineness of the mesh (global coarsenesse) to "very fine", locally at the level of the interface as shown in Fig. 7.

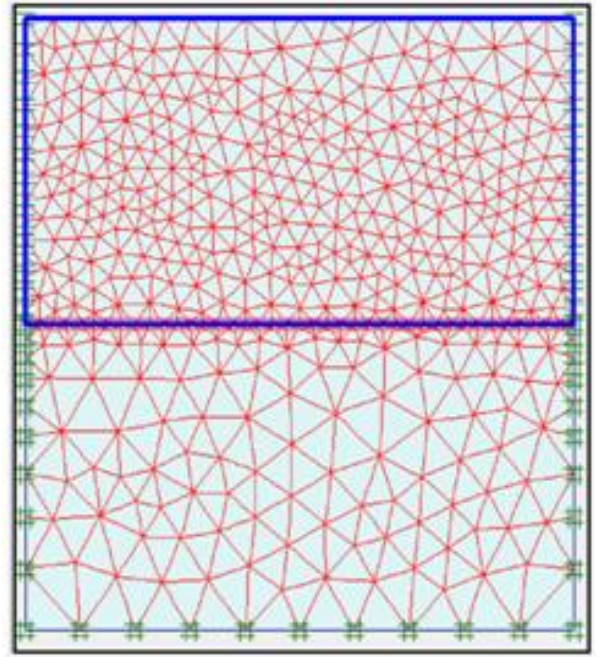

Fig. 7. Model mesh.

\section{T. Initial Conditions}

The initial conditions require the generation of the initial pore pressures as well as the initial stresses (Fig. 8).

\section{1) Initial stresses}

Initial stresses by taking the values of $\mathrm{K}_{0}$ by default and the value of $\mathrm{K}_{0}$ is automatically proposed according to the formula of Jaky. The weight of the soil is kept at 1 which corresponds to a total application of gravity.

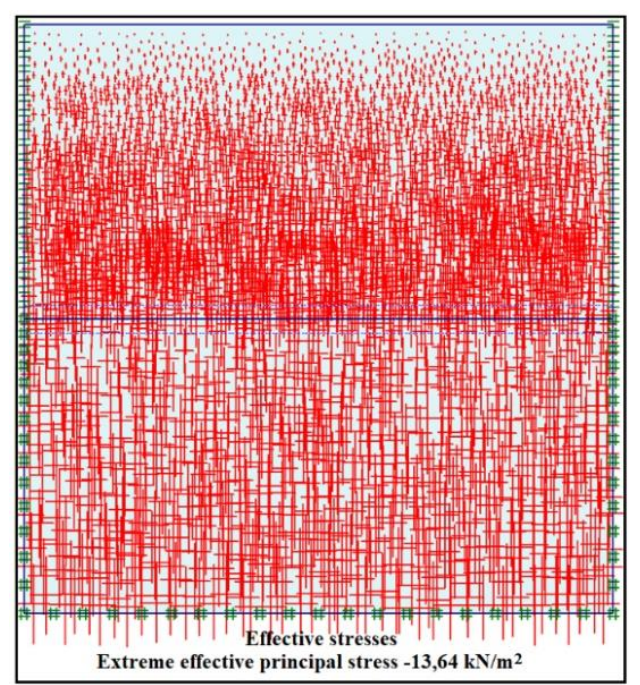

Fig. 8. Generation of the initial stresses.

\section{U. Calculation Procedure}

After defining a finite element model and generating the initial stresses, the actual calculations can be performed.

\section{RESULTS AND DISCUSSION}

\section{A. Experimental Results}

The parameters determined from laboratory tests are presented in Table IV. 
TABLE IV: RESULTS OF LABORATORY TESTS

\begin{tabular}{ccccc}
\hline Parameters & Symbol & Value & $\begin{array}{c}\text { Standard } \\
\text { deviation }\end{array}$ & Unit \\
\hline Specific density & Gs & 2,73 & 0,00 & --- \\
Maximum density & $\rho_{\max }$ & 1860 & 10,7 & $\mathrm{~kg} / \mathrm{m}^{3}$ \\
Minimum density & $\rho_{\min }$ & 1560 & 20,6 & $\mathrm{~kg} / \mathrm{m}^{3}$ \\
Planed internal & & & & \\
friction angle (large & $\varphi_{\text {gd' }}$ & 34,3 & --- & $\circ$ \\
deformation) & & & & \\
Angle of internal & & & & \\
friction planed at & $\varphi_{\text {pic }^{\prime}}$ & 43,2 & --- & $\circ$ \\
peaks (dense soil) & & & & \\
Angle of dilatancy & $\psi$ & 5,7 & 1,42 & $\circ$ \\
Sand portion & --- & 93 & --- & $\%$ \\
Silt portion & -- & 7 & --- & $\ldots$ \\
Plasticity Index & IP & 5.0 & $\ldots .$. & $\ldots$ \\
Cohesion & $\mathrm{c}$ & 1,7 & $\ldots .$. & $\mathrm{kPa}$ \\
\hline
\end{tabular}

\section{B. Modeling Results}

This section presents the results of the optimal numerical modeling based on the experimental tests. In order to verify and compare the results, a summary of the values obtained during the experimental session is presented in Table IV. To confirm the use of the numerical model it is necessary to compare the parameters controlled during the experimental tests such as vertical stress, lateral stress, and the ratio of the two $(\mathrm{K})$. These three parameters are used to verify and compare the numerical results with the experimental results.

\section{Model Validation}

The method presented above (2D) is used to study the shear strength of a low compressible unreinforced and reinforced soils by geosynthetics. The shear stresses are determined by considering the soil with and without reinforcement. Fig. 9 shows a comparison of the shear stresses obtained by the present study using the two methods (soil with and without reinforcement). It is interesting to note that the reinforcement of the soil by geosynthetic layers of stiffness $\mathrm{J}=500 \mathrm{kN} / \mathrm{m}$ increases the shear strength by around $8 \%$ (Fig. 9).

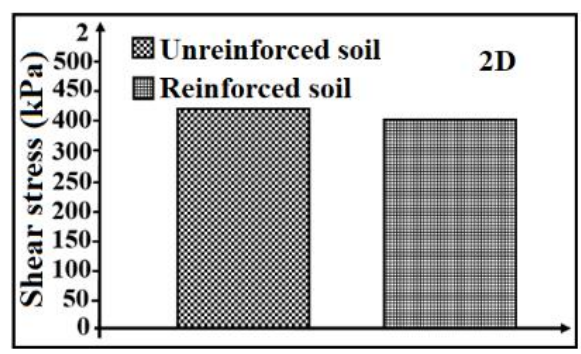

Fig. 9. Shear strengths Comparison.

\section{The Main Results of the Modeling}

We will be interested in two types of Strain: strain of form and internal strain such as:

1. Mesh strain.

2. Interface strain

\section{E. Mesh Strain}

The mesh and soil strain are shown in Fig. $10 \mathrm{a}$ and b. We note a maximum total displacement of $27.73 \times 10^{-3} \mathrm{~m}$.

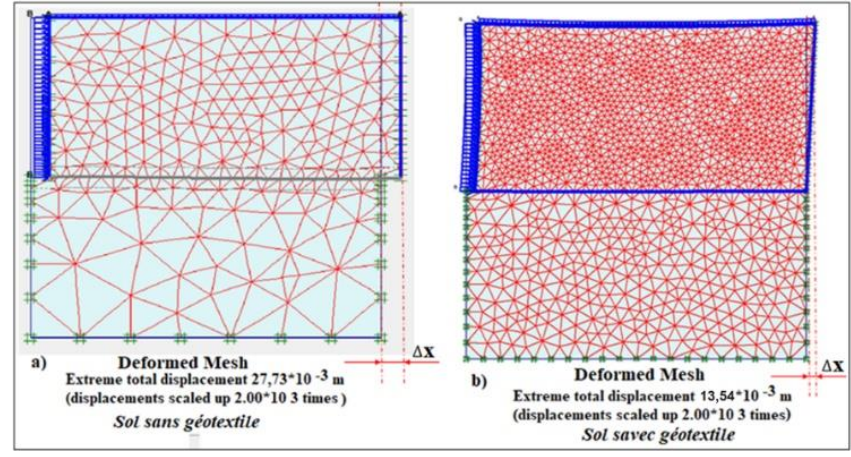

Fig. 10. Mesh strain.

In Fig. 10 we note that the displacements distribution is very consistent, they reach their maximum values on the area of application of the loads. We notice that these values are much higher in the case of an unreinforced soil, while a decrease of about $1 / 5$ is noticed in the case of a reinforced soil. This significant reduction is due to the change in the mechanical characteristics of the reinforced soil with the presence of geosynthetic layer or geotextile. The large displacement gradient clearly shows the benefit of the reinforcement.

It is clear that the two different approaches introduced in the present models give a significant difference between the results. Thus, the method with the soil without reinforcement gives a maximum displacement of 2.77 , on the other hand the method with reinforced soil gives a maximum displacement of $1.35 \mathrm{~m}$.

\section{F. Interface (Shear Plane)}

The maximum displacement is $2.77 \mathrm{~cm}$ with a maximum shear force of $114.34 \mathrm{KN} / \mathrm{m}^{2}$ (Fig. $11 \mathrm{a}$ and b).

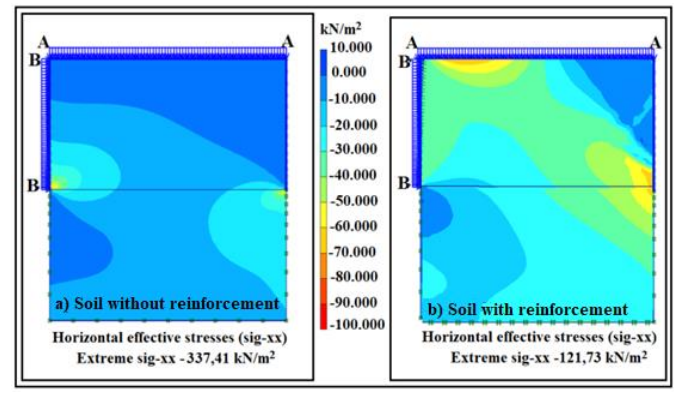

Fig. 11. Comparison of Maximum Shear Stresses

Fig. 11 shows the shear strain concentration surfaces obtained by different approaches used in the present study (soil with or without reinforcement). There is a discontinuous fracture surface obtained by the application of the two twodimensional models due to the discontinuity of the mechanical characteristics of the soil and the geosynthetics. Thus, the reinforcement significantly influences the rupture plane position.

\section{G. Parametric Study}

After results obtained by the present study considering different two models, we note that the two models (the soil with and without reinforcement) give shear strengths and failure planes in excellent agreement. Therefore, we adopt the two-dimensional model with soil reinforced by geosynthetics to examine the soil shear strength. 


\section{H. Geosynthetic Layer Stiffness Influence}

The apparent cohesion and the elastic characteristics of reinforced soils are directly linked to the geosynthetic layer stiffness. In fact, the greater the stiffness the less the soil deforms. For This new series of simulations, the value of geosynthetic stiffness varies from 0 to $3000 \mathrm{kN} / \mathrm{m}$. Fig. 12 shows the shear stress variation as a function of geosynthetic layer stiffness. It is important to note that the stiffness improves the soil strength increasing, therefore there is a decrease in the shear stress which leads to an increase in the shear strength.

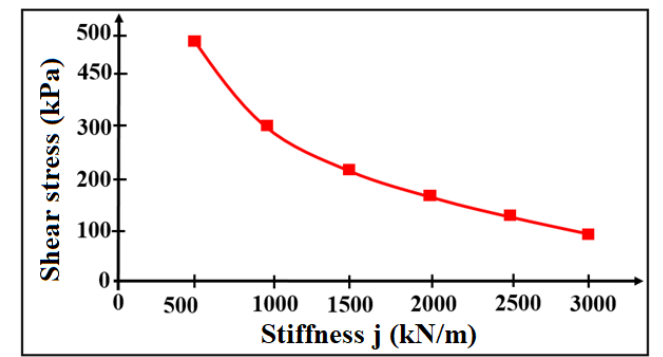

Fig. 12. Shear stress as a function of geosynthetic layer stiffness

\section{Discussion}

The geotechnical laboratory tests made it possible to assess the soil stress-strain behavior in the face of failure under reinforced or non-reinforced conditions. The results of Table 4 show that our soil is not very plastic, and it is very deformable. The engineering structures prevention against unexpected destruction prompted us to carry out simulations in order to better understand soils mechanics in the laboratory and to get an idea of reality. Thus, we compared two soil samples, one unreinforced and the other reinforced by geosynthetics. Thanks to the finite element method that we have been able to demonstrate that these results are in excellent agreement with the results published by other authors [1] because the greater the geosynthetic stiffness we achieve a geosynthetics fracture by bending that is equivalent to shear failure (Fig. 12).

\section{CONCLUSION}

The present work was devoted to the experimentalcharacterization and numerical identification of natural soil and reinforced soil with geosynthetics. It falls within the framework of improving and securing land in urban extensions.This research work is focused on soils reinforced behavior by geosynthetics and more particularly the interaction between soil and geosynthetic reinforcement. For this purpose, experimental tests of silty sand reinforced by a geosynthetic layer were carried out.

Conclusions are related to experimental and numerical developments carried out were drawn and summarized in the following points:

In the identification parameters study, in order to better present the physical aspects of the materials and to make a general classification of the soil, the identification tests confirm the presence of fine sand in our study area.

It is important to note that increasing the geosynthetic layer stiffness can significantly increase the soil shear strength. Eventually, increasing the stiffness and the friction angle of geosynthetic layer changes the soil behavior and the equivalent geosynthetics bending failure is achieved instead of shear failure.

\section{REFERENCES}

[1] A. Kempena, Water erosion risk assessment in Brazzaville City. Ph.D. Dissertation. Moa, Holguin, Cuba: Higher Institut of Mines and Matallurgy, 2017

[2] A. Sere, Reinforcement structures by geosynthetics with head loaded behaviour and dimensioning.Paris: HAL, 2010.

[3] N. R. Moraci, Factors affecting the interface apparent coefficient of friction mobilsed in pullout conditions. EuroGeo3, Munich, Germany, 2006

[4] B. Richa, Study by trivial dynamic of soils liquefaction by geosynthetics. Ph. D. dissertation. Grenoble, France: Joseph Fourier Grenoble 1 University, 1992.

[5] R. Brinkgereve, P. Vermeer, Plaxis Version 8, scientific manual, DELFT. Netherlands: University of Technology and Plaxis BV, 2003

[6] Jean, Shear stress. C 216. National School of Bridge and Roadway. Paris, 1996.

[7] J. M. Blivet, Soils shear stress determination in the laboratory, Trivia Test to device. National School of Bridge and Roadway, 1990.

[8] Z. Bendriss, Modeling of laboratory tests: Study of case: Study of reinforced soil by geosynthetics in the City of Bouinan, 2016. 